\title{
Calisthenics with Words: The Effect of Readability and Investor Sophistication on Investors' Performance Judgment
}

\author{
Xiao Carol Cui
}

Received: 30 November 2015; Accepted: 29 December 2015; Published: 5 January 2016

Academic Editor: Nicholas Apergis

School of Accountancy, Central University of Finance and Economics, 39 South College Road, Haidian District, Beijing 100081, China; xiao.carol.cui@gmail.com; Tel.: +86-131-2651-1468

\begin{abstract}
Since the 1990s, the SEC has advocated for financial disclosures to be in "plain English" so that they would be more readable and informative. Past research has shown that high readability is related to more extreme investor judgments of firm performance. Processing fluency is the prevalent theory to explain this: higher readability increases the investor's subconscious reliance on the disclosure, so positive (negative) news leads to more positive (negative) judgments. The relationship may not be so simple, though: drawing on research from cognitive psychology, I predict and find that investor financial literacy simultaneously influences investor decision-making, and that it has an interactive effect with readability. When presented with financial disclosure containing conflicting financial information, investors with higher financial literacy make more negative judgments than investors with low financial literacy when the disclosure is easy to read, but the effect becomes insignificant when the disclosure becomes difficult to read. This effect is moderated by a comprehension gap between the two investor groups. Financial literacy and readability interact to impact both how and how well the investor processes financial information.
\end{abstract}

Keywords: readability; financial literacy; management disclosures; textual information; investor decision-making

JEL Classification: G02

\section{Introduction}

In order to address concerns about disclosure readability, the SEC's Plain English Rule 421(d) went into effect in 1998 and requires that plain English principles be followed in firm prospectuses, ostensibly to encourage companies to better communicate and build relationships with investors because plain English is how individuals naturally process information. Further rules followed in 2006 and 2010, amending the Securities Exchange Act of 1934 and the Investment Advisers Act, respectively, to require the use of plain English in various financial disclosures and narrative brochures intended for future and prospective clients. Along with the 1998 rule, the SEC also issued the Plain English Handbook, which provides a practical guideline for preparing plain English disclosures. Linguistics choices are mostly related to diction or syntax, such as short sentences, active words, and simple synonyms. Formatting choices relate to layout, clear hierarchy of headings, tabulated information presented in bullet points, and appropriate use of tables and graphs.

However, while there is a robust and mature body of research in the existing body of accounting literature focusing on the incremental informativeness of textual information in financial disclosures, readability remains a developing field still in its nascent steps. Early studies ([1-3]) find that readability does have an effect on investors, acting especially upon small investors to limit their willingness or ability 
to extract information from financial disclosures. By taking an experimental approach, Rennekamp [4] and Tan, Wang and Zhou $[5,6]$ have gone further in studying readability and its influence on investor judgments and investor decision-making, by examining the cognitive influences that readability has on how investors process financial information. There remains, however, a dearth of research on the role that financial literacy might play in simultaneously also influencing investor judgments. While the SEC [7] believes that more readable disclosures should benefit "least-sophisticated" investors by making the financial information easier to read and to comprehend, there is still little empirical support for this assertion. Thus, this study attempts to fill the gap.

Research from cognitive psychology suggests that an individual's processing ability not only determine how well or efficiently they process information but also determines the method by which they choose to process information. Those with higher processing ability will choose to engage in deeper systematic analysis, while those with lower processing ability will more often choose to take advantage of mental shortcuts called heuristics, which conserve cognitive load but tend to rely on a more superficial level of analysis. Thus, when the cognitive load of a task is high-such as might be the case when there is an earnings release with conflicting financial indicators (some positive and some negative) that is presented in a difficult-to-read format-that is when we might see differentiation between the judgments of more and less sophisticated investors. Because the differentiation comes as a result of different ways of processing financial information, where deeper analysis is a pathway that is more likely to be activated by processing ability (i.e., financial literacy), the result is that there will be a sort of "comprehension gap" between the two investor groups. While processing fluency-the subjective feeling of positivity toward information that is easier to read-invariably mediates the judgment of both sophisticated and unsophisticated investors, understanding mediates only the high financial literacy group.

I design an experiment that examines the interaction between disclosure readability and investor financial literacy, to see if the idea of "readable disclosures helps least-sophisticated investors the most" is true. Participants are divided into high- and low-financial literacy groups based on demographic information, and all are presented with an earnings release that may be of high or low readability. All investors then judge the firm's future performance, and answer questions to test their understanding of the financial information and to gauge processing fluency. In response to financial information that is ultimately coded to display neutral firm performance, I find that more sophisticated investors with more readable disclosures make the lowest judgment while less sophisticated investors with less readable disclosures make the highest judgment, suggesting that readability and financial literacy both work independently and in tandem to mediate investors' judgment. Mediation analysis shows that, as predicted, processing fluency mediates both investor groups but understanding mediates only the high financial literacy group.

My results contribute to existing literature by identifying financial literacy as a factor that interacts with readability to influence financial judgment, and by further decomposing the readability effect by identifying the differing pathways by which readability exerts its influence on less sophisticated and more sophisticated investors. These are, however, perhaps not the results that the SEC might have hoped for: while readability absolutely does influence investors' judgments, it appears that it does so almost solely through more sophisticated investors-meaning that the "least-sophisticated" investors who are most at risk for getting bamboozled by verbal calisthenics appear to not get as much as could be hoped for out of financial disclosures written in plain English.

In Section 2, I provide a brief overview of existing research, outline the theoretical framework and develop my hypotheses. Section 3 presents my experimental design, including participation recruitment, experimental manipulations, and experimental procedure. Section 4 summarizes the results of my experiment, and provides analysis for tests of hypotheses. Section 5 concludes. 


\section{Background and Hypothesis Development}

\subsection{The Effect of Readability on Investors}

In archival accounting literature, there is evidence that disclosure readability affects investors and their decisions. You and Zhang [2] found that market under-reaction to 10-K filings becomes more severe as the report length increases (and readability decreases). Miller [3] focuses on small investors-those trading below $\$ 5000$ - and finds that high readability in $10-\mathrm{K}$ disclosures is associated with greater trading volume, while low readability in these disclosures reduces consensus in small investors but not in large investors. This evidence supports the SEC assertion that clear writing assists the "least-sophisticated investors" [7] in making judgments. A possible explanation for this effect is that small investors are less willing to or less able to extract information from a less readable financial disclosure [8-10].

Studies have used disclosure length as a measure of readability $[1-3,11]$. Length might not be the best measure of readability, though, because something written in plain English are generally shorter, and it is difficult to ascertain whether investors are reacting to an increase in readability or a decrease in disclosure length [4]. Other studies have used existing indices such as the Fox Index or Flesch Reading Ease Score [1,3,11-13], which calculate readability based on sentence length and number of syllables.

In general, research shows-and intuition agrees-that people like texts that feel easy to process, and because feeling experienced while thinking about a subject can very easily transfer to feelings about the subject itself, the subjective ease and comfort experienced in reading something with high processing fluency can be translated into a heuristic: if it is easy to read, it is good (i.e., reliable, dependable, true, etc.). Indeed, in psychology research, processing fluency has been linked to higher subjective ratings of truthfulness, preference for both message and messenger, willingness to rely on information presented, and confidence in judgments made based on information presented [14]. Consistent with this, Shah and Oppenheimer [15] find that more fluent information is weighed more heavily than less fluent information by individuals when they make judgments. Rennekamp [4] finds that more readable disclosures lead to stronger reactions from small investors, and that this result is mediated by the greater processing fluency from more readable disclosures, which act as a subconscious heuristic cue for investors to feel that they can trust and rely on the disclosure. Tan et al. [6] focus instead on how readability and consistency in benchmark performances interact. They find that when benchmark performance is inconsistent, readability has a greater impact on investor judgment than when the benchmark performance is consistent. They also find that when benchmark performance is inconsistent, readability affects performance judgments by impacting the participants' understanding rather than processing fluency.

\subsection{Heuristics and Decision-Making}

Low readability impedes the investor's understanding of performance benchmarks, and therefore also impedes their investment decision-making process. Realistically speaking, when there is good news, management would have neither the need nor the desire to obscure it, and thus would choose to present it accessibly. That way, they can convey good news the investors and ensure that they have as positive an opinion on the firm's performance as possible. Conversely, management has incentive to dilute the impact of negative news [1] by presenting the information in a way that is more difficult to understand, in the hopes that investors would have a harder time parsing through verbal calisthenics. In order to accomplish this, managers have been found to simultaneously manipulate both the language sentiment and the readability of disclosures [16,17]. Investors who do not glean the full scope of just how badly the company is doing would of course make a less negative judgment of the company's performance.

The focus of prior research has been on differences in the financial information and its presentation, and not on the investor's own ability to process information. Psychology research shows that decision-makers process information differently based on their level of processing ability. 
More specifically, when decision-makers have higher processing ability, they are more likely to engage in deeper systematic processing, but when decision-makers have lower processing ability they are more likely to take advantage of heuristics, which are strategic mental shortcuts that streamline the decision-making process and ease the cognitive load [18-20]. Thus, it is not either solely the content or solely the format of the financial disclosure that influences the investor's decisions; rather, the investor's own processing ability also plays a very crucial role.

In comparison to an earnings release that showcases consistently good or consistently bad performance indicators, one that presents conflicting financial information-for example, an earnings release that shows improvement in some financial indicators and deterioration in others-by its very nature requires a greater amount of analysis: it takes more attention to notice that a company with increasing revenue might actually be facing some challenges, as it requires more mental processing to realize that the rise in revenue is the cumulative result of aggressive expansion and decreasing customer volume and profit margins.

Interpreting conflicting financial information requires a higher cognitive load; parsing through jargon-filled and complexly structured low-readability disclosures likewise also increases cognitive load. This results in financial disclosures that are especially difficult to parse. Thus, when conflicting financial information is presented in a low-readability format, there should be no appreciable differences between the future performance judgments made by sophisticated (high financial literacy) and unsophisticated (low financial literacy) investors. When conflicting financial information is presented in a high-readability format, however, sophisticated investors will have a greater ability to engage in more thorough and in-depth analysis of the information, which would lead them to give deeper consideration to the "mixed signals" given out by financial indicators; the result is that they would make more negative evaluations of the company, while unsophisticated investors who have weaker processing ability would not make a significantly lower evaluation of the company. Thus, an interaction is predicted in my first hypothesis:

H1: Sophisticated investors make lower forecasts on the company's future performance than unsophisticated investors when the earnings release is easy to read. This difference in judgments becomes insignificant when firm performance is difficult to read.

Since sophisticated investors are more likely to engage with the information on a systematic and analytical level than their less sophisticated counterparts, the method in which the two groups process the information will lead to a comprehension gap. In other words, while processing fluency invariably plays a role for both groups, the difference in these respective evaluations of company performance is mainly attributable to a difference in understanding of the underlying financial information. Thus, I arrive at my second hypothesis:

H2: The aforementioned effect is mediated by a difference in understanding between sophisticated and unsophisticated investors.

\section{Method}

\subsection{Participants}

One hundred twenty-one participants are recruited through Amazon's Mechanical Turk (MTurk) platform, instead of through the recruitment methods of traditional laboratory experiments. On average, participants are 37 years old and have had 16.04 years of work experience, and the gender breakdown was $40 \%$ male and $60 \%$ female. They also have taken 1.9 accounting classes and 1.8 finance classes on average, and $73 \%$ have previously evaluated financial statements.

Miller [3] finds that retail investors (i.e., small investors) are especially influenced by the readability of disclosures, and the SEC emphasizes that its plain English recommendations are meant to help the "least-sophisticated investors" [7] —-therefore retail investors are an appropriate population for study in this experiment. After controlling for US residency and English as native language, 70\% of 
participants have prior experience investing, and on average, the number of accounting and finance courses completed by these participants are analogous to the number completed by actual average retail investors [21]. Therefore, participants recruited through MTurk are an appropriate proxy of retail investors, once appropriate screening procedures are implemented. Notable studies in accounting that have used MTurk participants include Koonce et al. [22], Rennekamp [4], and Rennekamp et al. [23].

\subsection{Experiment Design}

I use a $2 \times 2$ between-subjects design to test the hypothesis. The independent variables are financial literacy (more vs. less) and readability (high vs. low). The main dependent variable is the investors' predictions of firm performance.

All company information is generated for a fictional company based on a real company listed on the New York Stock Exchange (NYSE). Experimental manipulations are presented in the form of an earnings release, adapted from actual earnings releases issued by other listed companies from the same industry. This is necessary in order to prevent participants from recognizing the name of a particular real listed company and having a subjective reaction towards it, which would influence the assessment they make of the financial information presented to them.

The financial information itself is designed to show only small degrees of variation from the same quarter a year ago: changes across all financial indicators are between $-1 \%$ and $+2 \%$, resulting in current quarter performance that shows both positive and negative financial indicators but is essentially constant from the performance of the same quarter a year ago. This accomplishes the intended effect of providing participants with conflicting - thus complicated-financial information and thus increasing their cognitive load when processing the information, and also differs from past readability experiments that depend upon different performance conditions to show the directional effect that readability has on investor judgment. Instead, the quarter's performance is essentially coded to have not significantly changed from the performance of the same quarter a year ago, and does not provide any significant evidence that would lead the investor to feel that the company's performance will take a significantly positive or negative turn in the future. In the absence of such evidence, an investor who has understood the financial information (and grasped that the performance trend of the company has been flat) will more likely give a relatively neutral rating to the company's future prospects; an investor who has a lesser degree of understanding over the financial information, however, will more likely give a higher rating to the company's future prospects.

Two versions of the earnings release are used: they are either easy to read (high-readability) or difficult to read (low-readability), while the amount of information content being presented is held constant across both versions. As can be seen in the Appendix, the financial information contained in the releases is mixed, meaning that while some financial indicators show a decline from the same quarter last year (i.e., operating margin, earnings per share), other indicators show an improvement from that quarter (i.e., revenue).

\subsection{Manipulations}

Financial literacy of participants is measured based on demographic information, according to the method used by Tan et al. [5]. Participants are asked about the frequency with which they engage in investing behavior, number of accounting courses they have taken, number of finance courses they have taken, their frequency of reading annual reports, and their frequency of reading earnings releases. Standardized responses to these questions are summed up with equal weight, and this becomes the participant's sophistication score. Thus, the two financial literacy groups that comprise the independent variable are formed based on the median sophistication score: those with a lower score form the less financially literate (unsophisticated) group, while those with a higher score form the more financially literate (sophisticated) group.

The less financially literate group reports an average of 0.93 accounting classes and 0.89 finance classes taken, and an average reading frequency of 1.45 for annual reports and 1.55 for earnings releases. 
The more financially literate group reports an average of 2.85 accounting classes and 2.69 finance classes taken, and an average reading frequency of 2.63 for annual reports and 2.66 for earnings releases. Reading frequency is reported on a scale of 1 ("Never") to 5 ("Very Often"). The mean sophistication score for the low financial literacy group is -2.74 , while the mean score for the high financial literacy group is 2.69. For the whole set of participants, the minimum score is -5.93 , the maximum is 9.72 , while the median is 0.07 .

Readability is manipulated based on SEC [7] guidelines for plain English writing principles. More specifically, the high-readability version presents numbers-heavy financial information in tabular/bulleted form where applicable, uses short concise sentences and the active voice, and avoids both jargon and complicated technical terms. The low-readability version, on the other hand, presents the same set of numbers-heavy financial information in paragraph form, uses long complex sentences and the passive voice, and uses both jargon and complicated technical terms. Readability is manipulated while holding information content of the earnings releases constant.

\subsection{Procedure}

I ask all participants to assume the role of a general (i.e., nonprofessional) investor with an interest in the fictional company Piri Piri Grill, Inc. I provide them with information about the company that includes the company background, a recent four-year financial summary, and the most recent quarter's earnings release for the company. There are two versions of this earnings release, one that is easy to read (high readability) and one that is difficult to read (low readability), and participants are randomly assigned to either version (see the Appendix).

After reading the provided information package, participants answer a response questionnaire. Participants are asked to evaluate the firm's future performance using all information available to them. Specifically, they are asked to assess how strong the company's next-quarter performance will be, and how the stock price of the company will fare. Participants are then asked how plausible they find the financial information to be, whether they are willing to use this management-provided earnings release as the basis of their investment decisions regarding Piri Piri Grill. Finally, participants are debriefed.

\section{Results}

\subsection{Manipulation Checks}

To assess the effectiveness of the readability manipulations, participants were asked to rate whether the earnings release was easy to read and whether it was easy to understand. They rate both statements on an 11-point Likert scale, with $0=$ "not easy at all" and $10=$ "extremely easy". The mean ratings in the low readability condition were 4.48 and 4.13 for the easy-to-read and easy-to-understand measures respectively, while the mean ratings in the high readability condition were 6.21 and 5.54. The ratings are significantly higher for the high readability condition than they are for the low readability condition ( $p<0.01$ for reading and $p=0.01$ for understanding), suggesting that the participants perceive the high-readability version of the earnings release to be easier to read and process than the low-readability version of the release, which means that the readability manipulation is successful.

\subsection{Test of $H 1$}

I measure participants' evaluation of future firm performance by asking them to assess the extent to which they agree with a statement about the firm's performance being strong in the next quarter, and another statement about the firm's stock price rising in the near future. Participants are asked to identify their position on an 11-point scale, with " 5 " labeled as "strongly disagree", " 5 " labeled as "strongly agree", and " 0 " labeled as neutral. Their answers to these two questions are averaged, and the resultant score is used as the participant's judgment of future firm performance. The descriptive statistics are 
presented in Table 1, Panel A, and graphically depicted in Figure 1. As can be seen, when readability is low, there is no appreciable difference between the judgments of sophisticated and unsophisticated investors, and both judge the firm's future prospects to be significantly positive (2.30 and 2.47, respectively, both significantly greater than $0, p<0.01)$. When readability is high, however, the judgment of sophisticated investors drops drastically to $0.46(p=0.20$, not significantly different from 0 , indicating a neutral opinion of future performance) while the judgment of unsophisticated investors only dips slightly to $2.27(p<0.01)$. The difference in judgment scores between unsophisticated investors who received less readable disclosures (2.47) and sophisticated investors who received more readable disclosures $(0.46)$ is highly significant $(p<0.01)$.

$\mathrm{H} 1$ posits that investor judgment will be significantly lower for sophisticated investors than for unsophisticated investors when readability is high, but the difference will become insignificant when readability is low. To test the hypothesis, I conduct an analysis of variance (ANOVA) with readability and financial literacy as the two independent variables, and investors' assessment of future firm performance as the dependent variable. The ANOVA results are shown in Table 1, Panel B. I observe a significant effect of readability (2.39 vs. 1.44, $p<0.01)$, a significant effect of financial literacy (2.28 vs. 1.55, $p=0.01)$, and a significant interaction effect $(p<0.01)$.

Table 1. Descriptive Statistics and Analysis of Variance (ANOVA): Future Performance Judgments.

\begin{tabular}{|c|c|c|c|c|c|}
\hline \multicolumn{6}{|c|}{ Panel A: Descriptive Statistics: Mean (Standard Deviation) [Sample Size] } \\
\hline \multicolumn{6}{|c|}{ Readability } \\
\hline Financial Literacy & & \multicolumn{2}{|c|}{ High } & \multicolumn{2}{|c|}{ Overall } \\
\hline $2.30(2$ & $2.30(27)[2.10]$ & \multicolumn{2}{|c|}{$2.27(33)[1.34]$} & \multicolumn{2}{|c|}{$2.28(60)[1.71]$} \\
\hline $2.47(3$ & $2.47(33)[1.56]$ & \multicolumn{2}{|c|}{$0.46(28)[1.87]$} & \multicolumn{2}{|c|}{$1.55(61)[1.97]$} \\
\hline Overall & $2.39(60)[1.81]$ & & [1.83] & $1.91(12$ & [1.87] \\
\hline \multicolumn{6}{|c|}{ Panel B: ANOVA Tests of between-Subjects Effects } \\
\hline Source & S.S. & $d f$ & M.S. & F-statistic & $p$-value \\
\hline Readability & 30.87 & 1 & 30.87 & 10.54 & 0.00 \\
\hline Financial literacy & 20.05 & 1 & 20.05 & 6.85 & 0.01 \\
\hline Readability $\times$ Financial Literacy & 29.45 & 1 & 29.45 & 10.06 & 0.00 \\
\hline Error & 342.61 & 117 & 2.93 & & \\
\hline \multicolumn{6}{|l|}{ Panel C: Simple Main Effects } \\
\hline Source & & $d f$ & M.S. & F-statistic & $p$-value \\
\hline Financial literacy at low readabilit & level & 1 & 0.01 & 0.00 & 0.96 \\
\hline Financial literacy at high readabili & level & 1 & 60.92 & 21.03 & 0.00 \\
\hline Readability at low financial literac & level & 1 & 0.45 & 0.13 & 0.71 \\
\hline Readability at high financial litera & level & 1 & 49.54 & 19.42 & 0.00 \\
\hline
\end{tabular}

Participants are asked to indicate the extent to which they agree with the statements, "Piri Piri Grill's earnings performance will be strong in the next quarter" and "Piri Piri Grill's stock price will go up in the near future" on an 11-point scale, with " -5 " = "Strongly Disagree" and " 5 " = "Strongly agree". Because participants' judgments of earnings and stock price are highly correlated (coefficient $=0.88, p=0.00$; Cronbach's alpha $=0.94$ ), the two results are averaged for their judgment score. Panel A presents descriptive statistics, Panel B presents the results of the analysis of variance (ANOVA), and Panel C presents simple main effects of the two independent variables, readability and financial literacy. All $p$-values are two-tailed. 


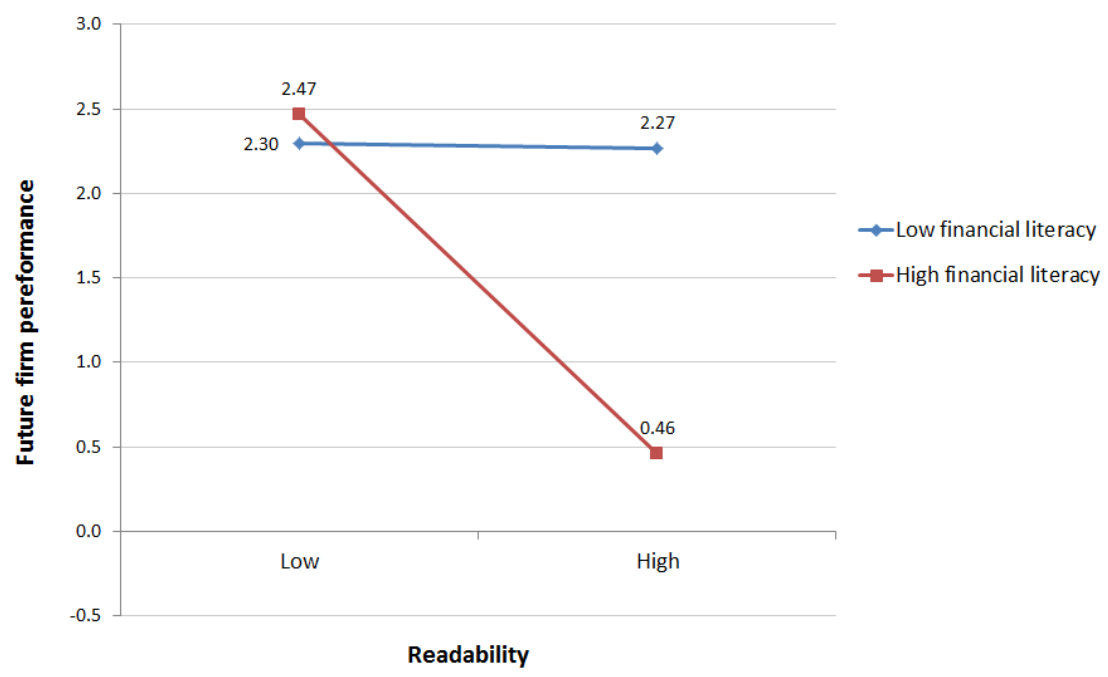

Figure 1. Plot of Readability-FinLit (Financial Literacy) interaction on change of future earnings performance judgment.

These results are further supported by simple main effects (Table 1, Panel C). When readability is low, the difference in judgments between unsophisticated and sophisticated investors is negligible ( 2.30 vs. $2.47, p=0.96$ ). However, when readability is high, the difference in judgments between the two investor groups becomes highly significant $(2.27$ vs. $0.46, p<0.01)$. Furthermore, for the low financial literacy group, the difference in judgments caused by differences in readability is insignificant (2.30 vs. 2.27, $p=0.71$ ) - while the high financial literacy group is highly sensitive to changes in readability $(2.47 v s .0 .46, p<0.01)$, with high readability bringing the judgments plummeting down.

\subsection{Test of $\mathrm{H} 2$}

$\mathrm{H} 2$ predicts that processing fluency mediates performance judgment for both the high financial literacy and the low financial literacy groups, but understanding only plays a mediating role in the former. In other words, $\mathrm{H} 2$ predicts that while all investors are invariably influenced by the way that higher readability leads to a higher degree of processing fluency, sophisticated investors also engage in deeper processing and analysis of the financial information and ultimately arrive at their judgment of future firm performance through a combination of both processing and understanding. Unsophisticated investors, on the other hand, are less likely to engage in such analysis, and thus processing fluency is the sole mediator for their judgment of future firm performance.

I measure participants' understanding of the financial information with three True or False questions about the financial information: a correct answer is coded as 1, an incorrect answer is coded as 0 , and the understanding score is the sum of three. I measure participant's processing fluency by asking them to assess the extent to which they agree with a statement about the earnings release being difficult to read, and another statement about the earnings release being difficult to understand. Participants are asked to identify their position on an 11-point scale, with " -5 " labeled as "strongly disagree", " 5 " labeled as "strongly agree", and " 0 " labeled as neutral. Their answers to these two questions are averaged, and the resultant normalized score is the participants' processing fluency score.

In order to test for H2, I perform mediation analysis through structural equation modeling (SEM), with readability as the independent variable and judgment of future firm performance as the dependent variable, with understanding and processing fluency both serving as the mediating variables. This is done for both understanding and processing fluency individually and in conjunction, at both levels of financial literacy. As can be seen in Figure 2, understanding (Panel A) does not play a role in mediating the unsophisticated investor's judgment (coefficient $=0.12, p=0.56$ ), but processing fluency (Panel B) 
does (coefficient $=1.93, p<0.01$ ). A further analysis of simultaneous mediation (Figure 3 ) confirms this, showing that understanding $(p=0.57)$ does not but processing fluency $(p<0.01)$ does mediate the relationship between readability and judgment, when the financial literacy of investors is low.

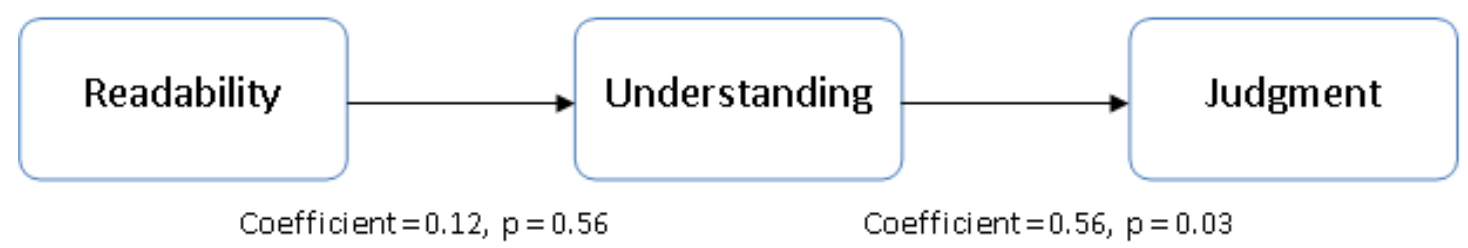

Panel A

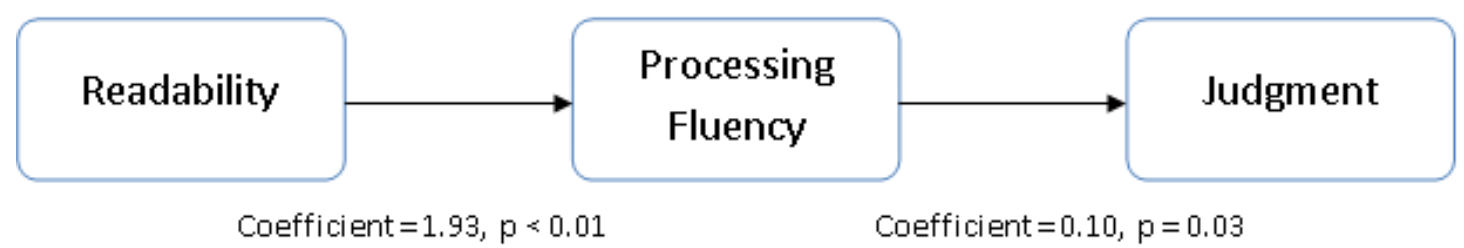

Panel B

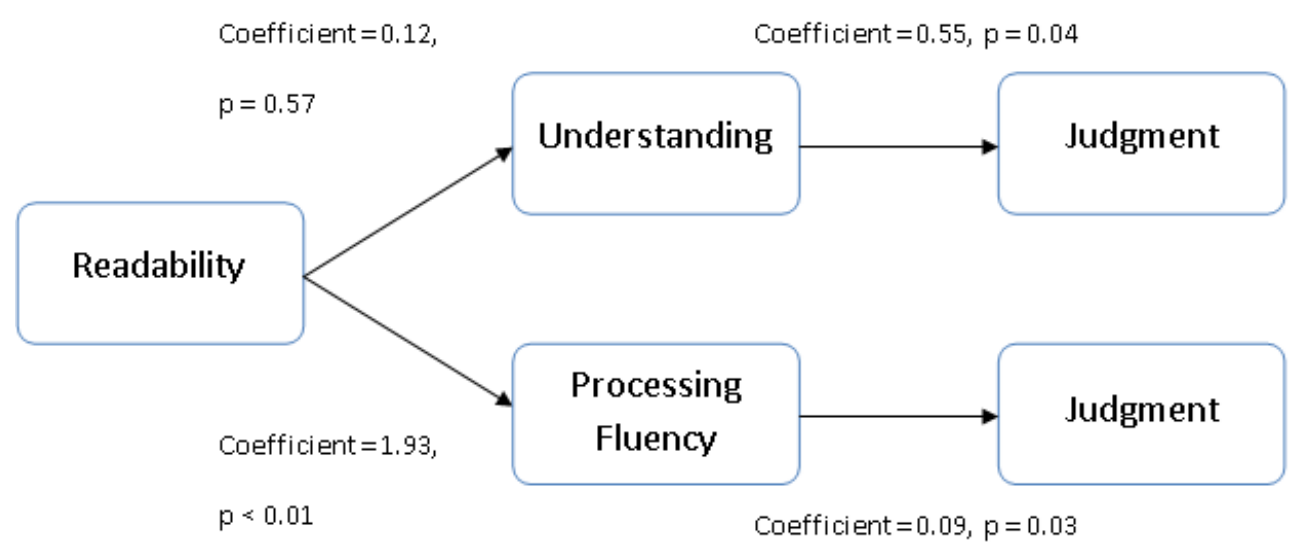

Panel C

Figure 2. This figure shows structural equation modeling (SEM) results for the mediating role of understanding (Panel A); processing fluency (Panel B); and both understanding and processing fluency simultaneously (Panel C) when investor financial literacy is low. I present the standardized coefficients and corresponding $p$-values next to each step. When financial literacy is low, the relationship between readability (independent variable) and future firm performance judgment (dependent variable) is mediated by processing but not understanding.

When readability is high, however, the results as outlined in Figure 3 look quite different: understanding (Panel A) plays a significant role in mediating the sophisticated investor's judgment (coefficient $=0.83, p<0.01$ ), and processing fluency (Panel $\mathrm{B}$ ) continues to do the same (coefficient $=1.62, p<0.01$ ). A further analysis of simultaneous mediation (Panel C) confirms this, showing that understanding $(p<0.01)$ and processing fluency $(p=0.01)$ both mediate the relationship between readability and judgment, when the financial literacy of investors is high. Thus, $\mathrm{H} 2$ is proven. 


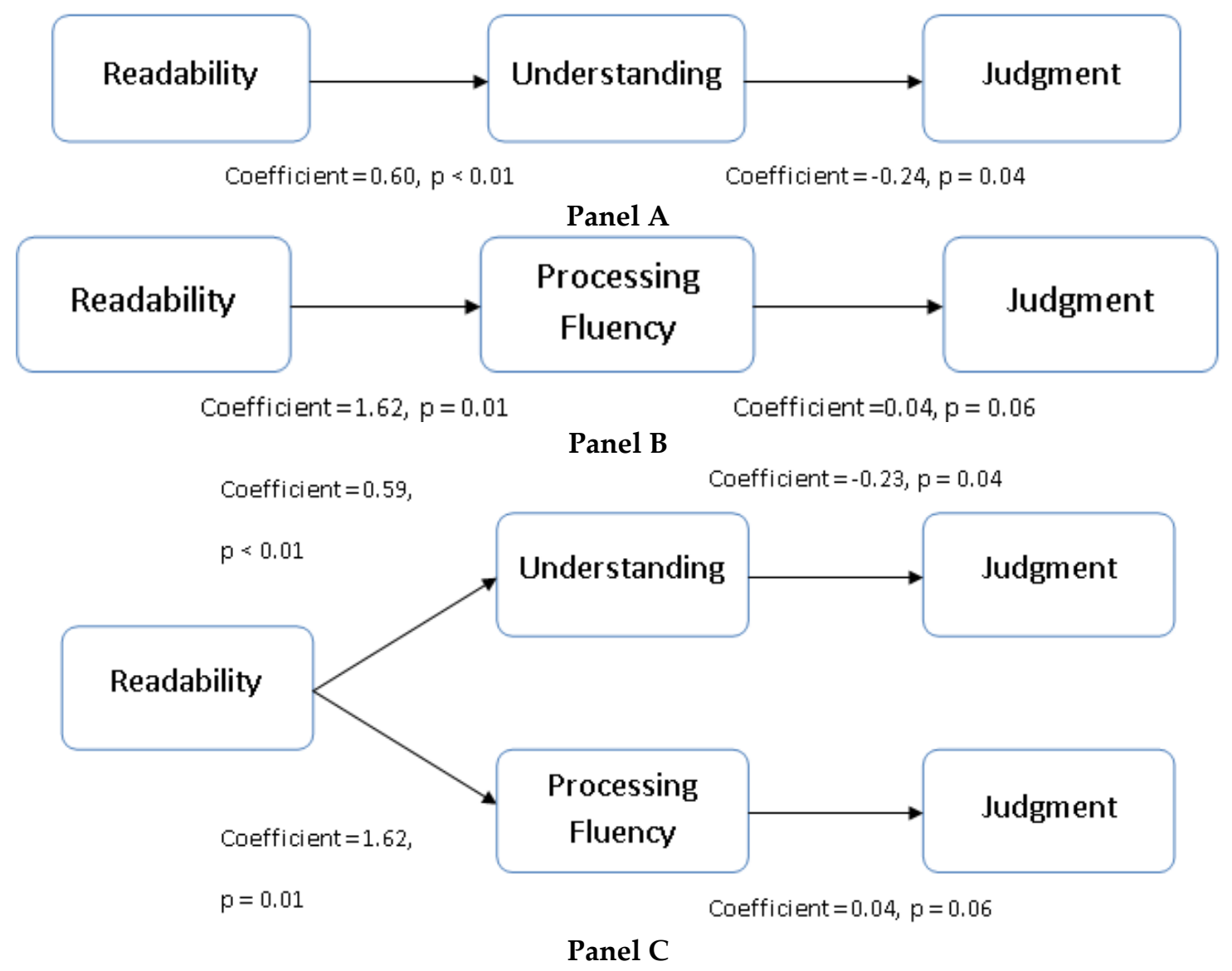

Figure 3. This figure shows structural equation modeling (SEM) results for the mediating role of understanding (Panel A); processing fluency (Panel B); and both understanding and processing fluency simultaneously (Panel C) when investor financial literacy is high. I present the standardized coefficients and corresponding $p$-values next to each step. When financial literacy is low, the relationship between readability (independent variable) and future firm performance judgment (dependent variable) is mediated by both understanding and processing.

\section{Conclusions}

In this study, I investigate how readability and financial literacy interact to influence investor judgments of future firm performance, and specifically choose to set my investigation in a scenario with "mixed" financial information, where some financial indicators show improvement while others show deterioration in performance. Overall, I find that readability does not influence investor judgment equally; instead, it has a highly significant effect on more financially literate investors, but the effect it has on less financially literate investors is diminished to the point of no longer being statistically significant. Judgments by the two investor groups do not differ significantly when readability is low, with both groups judging the firm's future firm performance to be relatively positive. At the high readability level, however, the difference becomes stark: while the judgment of the low financial literacy group does not significantly change, the judgment of the high financial literacy group drops significantly and becomes a neutral judgment instead.

These results are different from the Tan et al. [5] study, wherein they find that low readability obscures but does so with low-sophistication investors only, while high readability essentially establishes a baseline of both groups understanding the financial information. There may be several factors in play to explain this. Firstly, the two studies examine different main effects, with Tan et al. [5] focusing on the framing effect of positive tone as jointly moderated by investor sophistication and 
readability, while this study focuses on the main effect of readability on investors of differing sophistication levels. The way that the relationships between the variables are modeled in each study can potentially account in part for the differences in findings. Secondly, the experimental design is such that the stark contrast between positive tone and mixed-tending-negative performance in Tan et al. [5] is more "obvious" and thus may be easier to notice by investors of both sophistication levels than the mixed-tending-neutral performance in this study, particularly in the absence of highly contrasting linguistic sentiment in the disclosure, thus resulting in this more "subtle" effect being difficult to notice for investors even under the high-readability condition. Finally, though both studies employ acceptable proxies of retail investors, there may ultimately still exist a fundamental degree of difference between the investor sophistication of MTurk participants and MBA-student participants, which would exacerbate the sensitivity discrepancy outlined in the second point.

Further analysis shows that the difference in judgments between these two investor groups is a result of different mediating variables: while the relationship between readability and judgment is mediated only by processing fluency for the low financial literacy group, this relationship is mediated by both processing fluency and understanding for the high literacy group. Thus, this differentiation in mediating variables results in a sort of comprehension gap between the two investor groups.

This study contributes to the literature on readability by giving consideration to the role that financial literacy plays in influencing investor judgment, and uses this to provide a deeper level of analysis into the "magnifying" effect that high readability has on investor judgment of future firm performance. My results show that variations in readability do not affect all investors uniformly, and that the majority of the difference in judgment between readability levels is due to sophisticated investors, while the performance judgments of unsophisticated investors do not significantly differ between the two readability levels.

Furthermore, this study also expands upon theories of processing pathways for the readability-performance judgment relationship. Rennekamp [4] identifies processing fluency as the pathway through which readability operates, and Tan et al. [6] identify message consistency as being a key factor in specifying circumstances under which understanding as opposed to processing fluency is the mediating mechanism. This study further supports the findings by Tan et al. [5] in identifying financial literacy as another variable - this one focusing not on the financial information, but on the investors themselves-which could specify circumstances under which understanding plays a significant mediating role, and provide a more thorough understanding of just how readability works to influence investors in their judgments and decision-making.

Ultimately, however, this study has undeniable limitations. As opposed to extant research, this study presents investors with earnings releases that have only one level of financial performance, coded to be neutral with mixed indicators and insignificant deviations from the same quarter a year ago, rather than coded to show either positive or negative performance trend. While the difference in performance judgments between readability levels is significant for sophisticated investors, this might be describing a slightly different effect than the "magnifying" effect previously observed at the high readability level when the news is unambiguously good or unambiguously bad. Future research can investigate this issue by testing for readability and financial literacy at good performance and bad performance levels.

Conflicts of Interest: The author declares no conflict of interest.

\section{Appendix. Manipulation of Readability}

\section{A.1. Panel A: High-Readability Experimental Treatment}

Piri Piri Grill, Inc. Announces Second Quarter 2015 Results.

DENVER, CO-21 July 2015-Piri Piri Grill, Inc. (NYSE: PPG), a leader in the fast casual dining industry, today reported financial results for its second quarter ended 30 June 2015. 
The Table A1 below summarizes key financial highlights for the quarter ended 30 June 2015, as compared to the quarter ended 30 June 2014.

Table A1. Q3 2015 Results Summary for Piri Piri Grill (PPG).

\begin{tabular}{|c|c|c|c|c|}
\hline & $\begin{array}{l}\text { Quarter Ended } \\
30 \text { June } 2015\end{array}$ & $\begin{array}{l}\text { Quarter Ended } \\
30 \text { June } 2014\end{array}$ & Change & Reason \\
\hline Revenue & $\$ 1.17$ billion & $\$ 1.15$ billion & $+1.7 \%$ & $\begin{array}{l}\text { New restaurants, offset by decrease in } \\
\text { comparable restaurant sales }\end{array}$ \\
\hline $\begin{array}{l}\text { Change in Comparable } \\
\text { Restaurant Sales }\end{array}$ & $4.3 \%$ & $4.7 \%$ & $-0.4 \%$ & Decrease in customer volume \\
\hline Operating Margin & $28.0 \%$ & $28.2 \%$ & $-0.2 \%$ & Increasing administrative and food costs \\
\hline Earnings per Share & $\$ 4.45$ & $\$ 4.41$ & $+0.8 \%$ & $\begin{array}{l}\text { Driven by higher sales, offset by } \\
\text { decreasing operating margin }\end{array}$ \\
\hline
\end{tabular}

\section{Outlook}

Chief Executive Officer Alex Cunningham stated, "We feel good about our second quarter results, which exceeded our overall expectations. Our revenue and net income have continued to grow, even after a very strong 2014. This success is in spite of increasing administrative costs and fluctuating food costs that impact our operating margin, and a slight dip in customer volume. The strength of our business is the product of our unique food culture, which has helped us attract and retain a growing base of customers. We're doing very well, and we're constantly looking for ways to improve".

Our relentless focus on the key drivers of our business allows us to continue to change the way people think about and eat fast food. We are focused on pursuing the following initiatives:

- Phasing out genetically modified (GMO) ingredients

- Adding and maintaining good relationships with sustainably grown and ethical food suppliers

- Continuing to expand by opening new restaurants

- Creating and introducing innovative seasonal menu items

Cunningham added, "We expect further improvement in operations for the remainder of the year, especially as we roll out a nationwide price increase in the fourth quarter".

\section{A.2. Panel B: Low-Readability Experimental Treatment}

Piri Piri Grill, Inc. Announces Second Quarter 2015 Results.

DENVER, CO-21 July 2015-The summary presented below is of the performance for the quarter ended 30 June 2015, as compared to the quarter ended 30 June 2014, for Piri Piri Grill, Inc. (NYSE: PPG), a leader in the fast casual dining industry, as announced by the company today.

For the quarter ended 30 June 2015, revenue was $\$ 1.17$ billion, up $1.7 \%$ from the second quarter of 2014. The growth in revenue was driven simultaneously by revenue from new restaurants not in the comparable base and by a $4.3 \%$ increase in comparable restaurant sales. Comparable restaurant sales growth dipped from $4.7 \%$ in the same quarter last year, and was driven primarily by a decrease in customer volume. Restaurant level operating margin was $28.0 \%$ in the quarter, a decrease of 20 basis points from the second quarter of 2014. The drop was primarily driven by unfavorable sales leverage and increased administrative and food costs as a percent of revenue. Earnings were $\$ 4.45$ per share, a decrease of $1.8 \%$ over the $\$ 4.37$ per share from the second quarter of 2014 . This was the result of higher sales offset by decreasing operating margin.

\section{Outlook}

Alex Cunningham, CEO of Piri Piri, stated, "The second quarter results, which exceeded overall expectations, were encouraging for the Company. Even following a particularly strong 2014, and despite increasing administrative costs and fluctuating food costs that impact our operating margin as 
well as a slight dip in average check, there were beyond-expectations levels of growth for revenue, comparable restaurant sales, and net income. The Company recognizes that its core strength lies in the unique food culture that has been cultivated, and it is this core strength that enables the Company to both attract new customers and maintain high retention levels of repeat customers. The company recognizes the success that has been achieved in this current quarter, and is intent upon seeking out further avenues of improvement".

The Company remains focused on the key drivers that would allow for continuing changes to be made to the way people think about and eat fast food. In order to do this, the Company plans to continue phasing out genetically modified (GMO) ingredients, adding and maintaining good relationships with sustainably grown and ethical food suppliers, continuing to expand by opening new restaurants, and creating and introducing seasonal menu items.

Cunningham added, "Improvement in operations is expected for the remainder of the year, and these improvements should be especially noticeable as a nationwide price increase is to be implemented in the fourth quarter".

\section{References}

1. Li, F. Annual report readability, current earnings, and earnings persistence. J. Account. Econ. 2008, 45, 221-247. [CrossRef]

2. You, H.; Zhang, X.J. Financial reporting complexity and investor underreaction to 10-K information. Rev. Account. Stud. 2009, 14, 559-586. [CrossRef]

3. Miller, B.P. The effects of reporting complexity on small and large investor trading. Account. Rev. 2010, 85, 2107-2143. [CrossRef]

4. Rennekamp, K. Processing fluency and investors' reactions to disclosure readability. J. Account. Res. 2012, 50, 1319-1354. [CrossRef]

5. Tan, H.T.; Wang, E.Y.; Zhou, B. When the use of positive language backfires: The joint effect of tone, readability, and investor sophistication on earnings judgments. J. Account. Res. 2014, 52, 273-302. [CrossRef]

6. Tan, H.T.; Wang, E.Y.; Zhou, B. How does readability influence investors' judgments? Consistency of benchmark performance matters. Account. Rev. 2015, 90, 371-393. [CrossRef]

7. Securities, U.S.; Exchange Commission. A Plain English Handbook: How to Create Clear SEC Disclosure Documents. Available online: http:/ / www.sec.gov/pdf/handbook.pdf (accessed on 27 October 2015).

8. Grossman, S.J.; Stiglitz, J.E. On the impossibility of informationally efficient markets. Am. Econ. Rev. 1980, 70, 393-408.

9. Bloomfield, R.J. The "incomplete revelation hypothesis" and financial reporting. Account. Horiz. 2002, 16, 233-243. [CrossRef]

10. Hirshleifer, D.; Teoh, S.H. Limited attention, information disclosure, and financial reporting. J. Account. Econ. 2003, 36, 337-386. [CrossRef]

11. Loughran, T.; McDonald, B. When is a liability not a liability? Textual analysis, dictionaries, and 10-Ks. J. Finance 2011, 66, 35-65. [CrossRef]

12. Biddle, G.C.; Hilary, G.; Verdi, R.S. How does financial reporting quality relate to investment efficiency? J. Account. Econ. 2009, 48, 112-131. [CrossRef]

13. Lehavy, R.; Li, F.; Merkley, K. The effect of annual report readability on analyst following and the properties of their earnings forecasts. Account. Rev. 2011, 86, 1087-1115. [CrossRef]

14. Alter, A.L.; Oppenheimer, D.M.; Epley, N.; Eyre, R.N. Overcoming intuition: Metacognitive difficulty activates analytic reasoning. J. Exp. Psychol. Gen. 2007, 136, 569-576. [CrossRef] [PubMed]

15. Shah, A.K.; Oppenheimer, D.M. Easy does it: The role of fluency in cue weighting. Judgm. Deci. Mak. 2007, 2, 371-379.

16. Henry, E. Are investors influenced by how earnings press releases are written? J. Bus. Commun. 2008, 45, 363-407. [CrossRef]

17. Rogers, J.L.; van Buskirk, A.; Zechman, S.L. Disclosure tone and shareholder litigation. Account. Rev. 2011, 86, 2155-2183. [CrossRef] 
18. Chaiken, S. Heuristic versus systematic information processing and the use of source versus message cues in persuasion. J. Personal. Soc. Psychol. 1980, 39, 752-766. [CrossRef]

19. Chaiken, S.; Liberman, A.; Eagly, A.H. Heuristic and systematic processing within and beyond the persuasion context. In Unintended Thought, 2nd ed.; Uleman, J.S., Bargh, J.A., Eds.; Guilford: New York, NY, USA, 1980; pp. 212-252.

20. Petty, R.E.; Cacioppo, J.T. Source factors and the elaboration likelihood model of persuasion. Adv. Consum. Res. 1984, 11, 668-672.

21. Elliott, W.B.; Hodge, F.D.; Kennedy, J.J.; Pronk, M. Are MBA students a good proxy for nonprofessional investors? Account. Rev. 2007, 82, 139-168. [CrossRef]

22. Koonce, L.; Miller, J.; Winchel, J. The effect of norms on investor reactions to derivative use. Contemp. Account. Res. 2015, 32, 1529-1554. [CrossRef]

23. Rennekamp, K.; Rupar, K.; Seybert, N. Impaired judgment: The effects of asset impairment reversibility and cognitive dissonance on future investment. Account. Rev. 2015, 90, 739-759. [CrossRef]

(C) 2016 by the author; licensee MDPI, Basel, Switzerland. This article is an open access article distributed under the terms and conditions of the Creative Commons by Attribution (CC-BY) license (http:/ / creativecommons.org/licenses/by/4.0/). 